\title{
Synthesis and properties of epoxy-phenolic clay nanocomposites
}

\author{
M. L. Auad ${ }^{*}$, S. R. Nutt ${ }^{2}$, V. Pettarin ${ }^{3}$, P. M. Frontini ${ }^{3}$ \\ ${ }^{1}$ Auburn University, Polymer and Fiber Engineering Department, 103 Textile Building Auburn, AL 36849, U.S. \\ 2University of Southern California, Materials Science Department, Gill Foundation Composites Center 3651 Watt Way, \\ VHE-602 Los Angeles, CA 90089-0241, U.S. \\ 3Instituto de Ciencia y Tecnología de Materiales (INTEMA), CONICET Universidad Nacional de Mar del Plata, Juan B. \\ Justo 4302, B7608FDQ Mar del Plata, Argentina
}

Received 25 May 2007; accepted in revised form 7 August 2007

\begin{abstract}
An epoxy-phenolic resin suitable for use as a composite matrix was reinforced with modified nanoclay (montmorillonite type). Characterization by x-ray diffraction and transmission electron microscopy (TEM) demonstrated that intercalated nanocomposites were formed with an inter-gallery distance of approximately $10 \mathrm{~nm}$. The influence of nanoparticles on tensile strength and modulus, fracture toughness, and impact toughness was measured and compared with the unreinforced polymer. The results revealed that the maximum enhancement in stiffness and toughness was achieved with $2.5 \mathrm{wt} \%$ filler content. The enhancement in toughness behavior was attributed to the activation of multiple energy-dissipating damage mechanisms in the nanocomposites.
\end{abstract}

Keywords: nanocomposites, epoxy-phenolic, layered silicates

\section{Introduction}

Polymer/clay nanocomposites offer the possibility of improved properties which cannot be matched by micron-sized filler particles, such as conventional talc and glass fillers [1-5]. Nanocomposites reportedly show enhanced tensile and thermal properties [1-8], heat distortion temperature [1-5], resistance to flammability $[9,10]$, and reduced permeability to small molecules $[4,11,12]$ and solvent uptake [13]. These enhancements are partly attributable to the extremely large particle surface area available for interaction with the polymeric matrix, coupled with a high aspect ratio (between 30 and 2000) [14]. The property improvements resulting from the formation of a nanocomposite occur at relatively low concentrations of clay (generally 2-5 wt \%) compared to conventional filled polymer composites, which often contain 20-30 wt \% of filler. In addition to enhanced performance, clay nanocomposites are easily extruded or molded to near-net shape, simplifying the manufacturing process.

For the reasons noted above, polymer nanocomposites are likely to find a wide range of new applications in reinforced lightweight structural components, non-linear optics, battery cathodes, nanowires, sensors and other systems. Transportationoriented applications that require weight savings are also likely, including airplane interiors, fuel tanks, and structural components of air and land vehicles [15].

The two major steps involved in dispersing clay nanoparticles in polymers are intercalation and exfoliation [6]. In the intercalation step, the spacing between individual clay layers increases as polymer chains or monomer molecules diffuse into the 
clay galleries. Intercalation can be facilitated by specific treatments of clay particles with organic modifiers. In exfoliation, the individual clay particles separate from the intercalated tactoids and are dispersed in the matrix polymer, forming a monolithic structure [16].

Up to now, extensive research on general polymer layered silicate nancomposites has been carried out $[7,11,17,18]$. Epoxy/clay has been one of the most studied systems, where merely intercalated or exfoliated structures were obtained $[6,8,10]$. On the other hand exfoliation has been reported for several polymer matrixes, such as polyimide [4, 7], polyaniline [19], nylon [20] and phenolic [21, 22]. However, there is no reported research on EpoxyPhenolic/clay system. Compared with the epoxy or phenolic systems, epoxy-phenolic based nanocomposites offer some intriguing benefits, including both flame-resistance and low cost. In addition, phenolic-epoxy networks can exhibit acceptable mechanical properties [23, 24]. Because of the void-free nature of these materials combined with tailored crosslink densities, these thermosets can exhibit toughness comparable to or exceeding untoughened aerospace epoxies while maintaining flame retardant properties approaching those of pure phenolic polymers [23, 24]. For these reasons, E-P resins are also attractive for use in airplane interiors. Adding nano-fillers, such as nanoclay, can greatly improve the mechanical and thermal properties of these systems.

In this work, we report the preparation methods and characterization of epoxy-phenolic clay nanocomposites with varying percentages of nanoclay filler. The intent is to establish the structure-property relations in this system. The nanostructure is verified by x-ray diffraction (XRD) and by transmission electron microscopy (TEM). Mechanical properties and fracture behavior are measured and related to observed microstructures.

\section{Experimental}

\subsection{Materials and sample preparation}

A montmorillonite type nanoclay modified with methyl tallow bis-2-hydroxyethyl quaternary ammonium chloride (Southern Clay Products, Cloisite 30B) was selected for this study. Epoxy-phenolic (E-P) networks were synthesized by reacting a novolac type phenolic resin (Georgia Pacific, labo- ratory grade reagent) and an epoxy resin, diglycidyl ether of bisphenol A (Epon 828, equivalent weight $187 \mathrm{~g} / \mathrm{eq}$.), using $0.3 \mathrm{wt} \%$ of triphenylphosphine as catalyst (Fluka A. G., analytical reagent). The amount of catalyst added is reported based on the weight of epoxy. The curing E-P reaction proceeds via nucleophilic addition of the phenolic hydroxyl onto the epoxy group [25-27].

As-received clay was dried in a vacuum oven for 24 hours at $100^{\circ} \mathrm{C}$, then mixed with different epoxy-to-phenolic ratios as shown in Table 1. To prepare the samples, the epoxy was first dried at $80^{\circ} \mathrm{C}$ under vacuum for 24 hours. The resulting mixture was blended using an orbital mixer (Keyence) for 30 minutes. After this step, the samples were sonicated at $60^{\circ} \mathrm{C}$ for 1 hour and placed in an oven for 12 hours at $60^{\circ} \mathrm{C}$. Next, the mixtures were blended with the novolac at $140^{\circ} \mathrm{C}$ for $30 \mathrm{~min}$ utes. Finally, the catalyst was added and the mixtures were placed in closed molds. The curing reaction was carried out in a conventional oven at $180^{\circ} \mathrm{C}$ for 1 hour and at $200^{\circ} \mathrm{C}$ for 30 additional minutes.

Table 1 provides details of the weights and equivalent weight percentages of epoxy-to-novolac used for this work. Also given in Table 1 are the identification codes assigned to the fabricated materials. Different amounts of clay $(0,1,2.5,5$ and $10 \mathrm{wt} \%)$ were used for sample preparation.

Table 1. E-P formulation

\begin{tabular}{|c|c|c|}
\hline Formulation & E-P [eq./eq.] & E-P [wt \%/wt \%] \\
\hline E-P(67/33) & $1 / 1$ & $67 / 33$ \\
\hline E-P(50/50) & $1 / 2$ & $50 / 50$ \\
\hline E-P(35/65) & $1 / 4$ & $35 / 65$ \\
\hline
\end{tabular}

\subsection{Characterization}

$\mathrm{X}$-ray diffraction patterns were acquired using $\mathrm{Cu}$ $\mathrm{K} \alpha$ radiation in the $2 \theta$ range $3^{\circ}-14^{\circ}$, with a scanning rate of $5 \%$ min (Rigaku RV20 diffractometer). Transmission electron microscopy (TEM) was performed at an accelerating voltage of $100 \mathrm{kV}$ (JEOL $100 \mathrm{CXII})$ on $\sim 100 \mathrm{~nm}$ thick sections, microtomed from samples containing 2.5 and $5 \mathrm{wt} \%$ clay. Micrographs of the fracture surfaces of the different materials were recorded using a scanning electron microscope operated at $15 \mathrm{kV}$ (Cambridge 360 SEM). Fractured specimens were coated with gold to impart electrical conductivity. 


\subsubsection{Thermal analysis}

The glass transition of the samples was determined as the temperature corresponding to the maximum in the $\tan \delta$ curve. Thermo-mechanical response of the cured resins was determined using a dynamical mechanical analyzer (TA Instruments, Newark, Delaware). Beam samples were cut to $3 \mathrm{~mm} \times$ $5.5 \mathrm{~mm} \times 60 \mathrm{~mm}$ and clamped in the frame using dual cantilever mode. For analysis, samples were heated from 25 to $300^{\circ} \mathrm{C}$ at a rate of $10^{\circ} \mathrm{C} / \mathrm{min}$, and cyclic load was applied at a frequency of $10 \mathrm{~Hz}$.

\subsubsection{Mechanical properties}

Mechanical tests were carried out at room temperature using a universal testing machine (Instron model 4467). The flexural tangent elastic modulus and strength were determined in accordance with standard methods (ASTM D790M) using a loading rate of $1.7 \mathrm{~mm} / \mathrm{min}$. The compressive yield behavior was determined using cylindrical specimens, with an aspect ratio of 3 . Specimens were machined from samples molded in glass tubes. Care was taken to obtain smooth and parallel faces. Uniaxial compression tests were performed at a loading rate of $0.5 \mathrm{~mm} / \mathrm{min}$ following ASTM 695 .

Fracture toughness was determined using a single edge notched (SEN) type specimen $(6.4 \mathrm{~mm} \times$ $12.7 \mathrm{~mm} \times 60 \mathrm{~mm}$ ) and applying conventional linear elastic fracture mechanics to determine the critical stress intensity factor in plane strain, $K_{1 C}$. Tests were performed according to ASTM D5045-93. After making a notch at the center of the sample with a reciprocating saw, a sharp crack of length $a$ was initiated by tapping a fresh razor blade into the notch tip at room temperature. Samples were loaded in a 3-point bending fixture at a crosshead speed of $10 \mathrm{~mm} / \mathrm{min}$. The mean value of at least eight samples was reported. From load-displacement plots and known crack lengths, the stress intensity factor, $K_{1 C}$, was computed at a maximum load $(P)$. Equation (1) was used, where $f(a / W)$ is a dimensionless function of the ratio $a / W$ (Equation (2)) is a, given by ASTM D5045, $W$ is the specimen height, and $B$ is the thickness.

$K_{1 C}=\frac{f(a / W) P}{B \cdot W^{1 / 2}}$

where $f(a / W)=$
$6 \frac{a^{1 / 2}}{W} \frac{\left[1.99-\frac{a}{W}\left(1-\frac{a}{W}\right)\left(2.15-3.93 \frac{a}{W}-2.7 \frac{a^{2}}{W}\right)\right.}{\left(1+2 \frac{a}{W}\right)\left(1-\frac{a}{W}\right)^{3 / 2}}$

In order to analyze the damage zone around the crack tip, the double-notch four-point-bend (DN4PB) technique was used (Figure 1). Two edge cracks of approximately equal length were generated in the specimen $(64 \mathrm{~mm} \times 12.7 \mathrm{~mm} \times 125 \mathrm{~mm})$. The specimen was then loaded in a four-point bending fixture at a crosshead speed of $10 \mathrm{~mm} / \mathrm{min}$, locating the two pre-cracks within the minor span on the tensile side. Owing to stress intensification at the crack tips, a plastic zone formed independently at each crack tip upon loading (the pre-crack spacing exceeded the size of the plastic zone). Because the pre-cracks were not identical, one precrack become critical and propagated in an unstable manner, thus unloading the other crack that was immediately arrested.

Transmitted optical microscopy, TOM, was employed to examine the damage zone around the surviving crack tip. Thin sections were obtained using conventional grinding-polishing techniques $[28,29]$. First, a block was cut by sectioning normal to the fracture surface but parallel to the direction of crack propagation. The block was encapsulated in epoxy and cured at room temperature. Samples were finely ground and polished. The

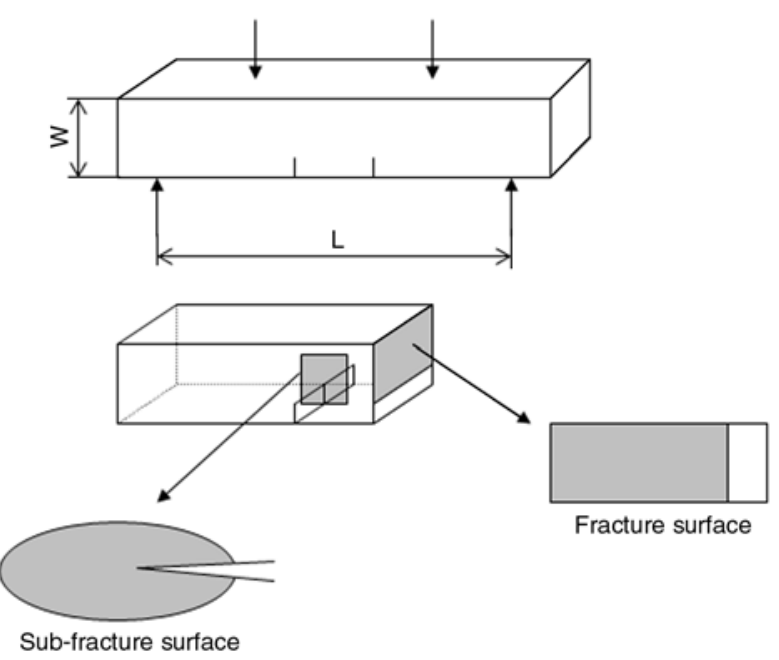

Figure 1. Scheme of the double-notch four-point-bend (DN-4PB) technique 
polished surface was mounted onto a clean glass slide using an optically clear epoxy that was allowed to cure overnight at room temperature. The sample was again ground and polished until the plane of interest was finally reached. The thickness of the final material ranged from 150 to $350 \mu \mathrm{m}$. Optical micrographs were recorded using a transmission microscope, with and without crossedpolarizers.

Charpy-type impact tests were performed in an instrumented falling weight impact tester (Fractovis, Ceast). Rectangular, V-notched specimens with nominal dimensions $S \times W \times B$ equal to $80 \times$ $10 \times 6 \mathrm{~mm}$ were struck by an impactor mass of $3.6 \mathrm{~kg}$ at an impact speed of $1 \mathrm{~m} / \mathrm{s}$, corresponding to an impact energy of $1.8 \mathrm{~J}$ at room temperature. Impact strength was calculated as the ratio between energy consumed (area of the load vs. deformation curve) and resistant area of the sample (ASTM D256). The distance between supports was set to $70 \mathrm{~mm}$. The average of results obtained from 10 samples per material was reported as the impact strength.

\section{Results and discussion}

\subsection{Morphology of E-P/clay nanocomposites}

XRD was used to monitor the expansion behavior of the silicate layers after curing of the nanocomposites. The $\mathrm{x}$-ray scattering intensities for the organically modified clay (Cloisite 30B) and the E$\mathrm{P}$ nanocomposites containing different amounts of clay are shown in Figure 2. The diffraction pattern for the pure clay shows a peak corresponding to the basal plane spacing of $1.54 \mathrm{~nm}$ for the organically

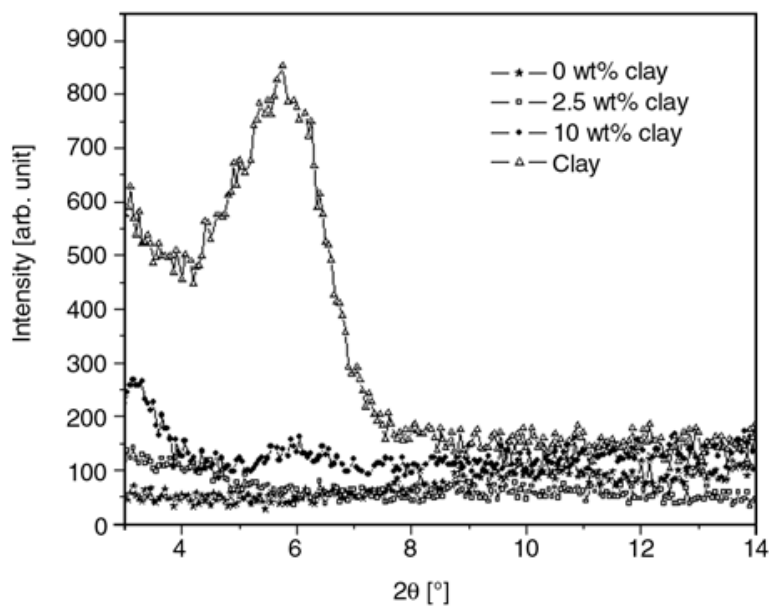

Figure 2. X-ray diffraction pattern for the E-P/clay nanocomposites. Sample: E-P(35/65) modified montmorillonite. After the curing process, none of the samples show this basal plane peak, indicating that exfoliation or intercalation has occurred in the system.

TEM experiments allow the morphological state of the nanocomposite to be delineated more completely. Montmorillonite clay consists of hierarchy structures, of which the individual aluminosilicate sheets ( 1 nm thick) may be considered the structural unit. Several sheets stacked face to face with an interlayer charge balancing cation lead to a stack and an agglomeration of these stacks leads to the macroscopically observable micron-sized particles. Therefore, each macroscopic particle of clay is actually comprised of many individual aluminosilicate sheets. Consequently, the formation of a nanocomposite involves the break-up and dispersion of the agglomerated stacks of sheets followed by the swelling of the gallery spacing between the sheets by the polymer and the monomers. Figure $3 \mathrm{a}$ and $3 \mathrm{~b}$ show transmission electron micrographs of the E-P nanocomposite containing $2.5 \mathrm{wt} \%$ clay. At low magnifications, some aggregates of clay layers were present in the composites (Figure 3a). However increasing the magnification in an area occupied by an aggregate reveals the individual sheets of clays clearly separated by a layer of E-P polymer as showed in Figure 3b. It is evident that in general, the nanostructures consisted primarily of layered sheets rather than exfoliated single sheets. That is, there are regions where the regular stacking arrangement is maintained with a layer of polymer between the sheets, and also regions where completely delaminated sheers are dispersed individually. The distance between the layers was approximately $10 \mathrm{~nm}$. This long-range ordered structure is typical of thermoset, layered silicate nanocomposites synthesized via in-situ polymerization [30].

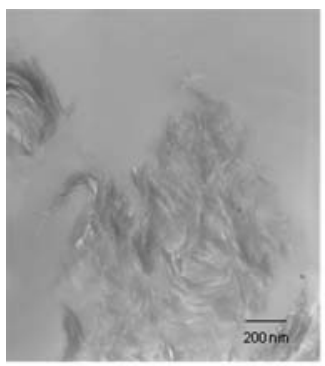

a)

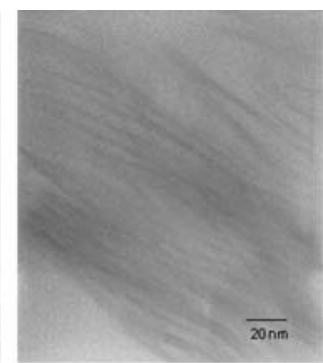

b)
Figure 3. TEM image of E-P/clay nanocomposite containing $2.5 \mathrm{wt} \%$ of clay. Sample: E-P(35/65). a) line: $200 \mathrm{~nm}, \mathrm{~b})$ line: $20 \mathrm{~nm}$ 
Table 2. Changes in thermal, flexural and compressive behavior of the clay reinforced E-P samples

\begin{tabular}{|c|c|c|c|c|c|}
\hline \multirow{2}{*}{ Matrix } & \multirow{2}{*}{$\begin{array}{l}\text { Clay } \\
{[w t \%]}\end{array}$} & \multirow{2}{*}{$\begin{array}{c}\text { Thermal properties } \\
\mathbf{T}_{\mathrm{g}}\left[{ }^{\circ} \mathbf{C}\right]\end{array}$} & \multicolumn{2}{|c|}{ Flexural properties } & \multirow{2}{*}{$\begin{array}{c}\text { Compression properties } \\
\text { Strength [MPa] }\end{array}$} \\
\hline & & & Modulus [MPa] & Strength [MPa] & \\
\hline \multirow{5}{*}{ E-P $(67 / 33)$} & 0 & 139.5 & $3516.1 \pm 15.9$ & $121 \pm 3.1$ & $144.5 \pm 9.2$ \\
\hline & 1 & 128.0 & - & $120 \pm 1.2$ & - \\
\hline & 2.5 & 127.6 & $3800.3 \pm 57.2$ & $117 \pm 2.5$ & $73.6 \pm 13.6$ \\
\hline & 5 & 126.9 & $3960.6 \pm 36.2$ & $124 \pm 2.2$ & $57.6 \pm 8.4$ \\
\hline & 10 & 132.3 & $4054.1 \pm 105.4$ & $114 \pm 1.6$ & $50.4 \pm 15.2$ \\
\hline \multirow{5}{*}{ E-P $(50 / 50)$} & 0 & 141.0 & $3757.3 \pm 217.9$ & $135.1 \pm 3.4$ & $79.6 \pm 8.2$ \\
\hline & 1 & 144.8 & $3549.2 \pm 102.3$ & $122.3 \pm 1.3$ & $76.2 \pm 29.6$ \\
\hline & 2.5 & 144.7 & - & $120.5 \pm 2.1$ & - \\
\hline & 5 & 143.7 & $3709.0 \pm 164.0$ & $127.9 \pm 1.3$ & $76.0 \pm 7.1$ \\
\hline & 10 & 141.6 & $4260.4 \pm 216.4$ & $119.4 \pm 1.8$ & $63.5 \pm 4.7$ \\
\hline \multirow{5}{*}{ E-P $(35 / 65)$} & 0 & 122.8 & $4147.9 \pm 297.8$ & - & $82.03 \pm 20.4$ \\
\hline & 1 & 118.4 & $4533.4 \pm 494.2$ & - & $66.1 \pm 13.3$ \\
\hline & 2.5 & 116.7 & $4645.9 \pm 114.5$ & - & $52.1 \pm 4.6$ \\
\hline & 5 & 119.4 & - & - & - \\
\hline & 10 & 116.6 & $4826.7 \pm 162.7$ & $\begin{array}{ll}- \\
-\end{array}$ & $30.9 \pm 9.2$ \\
\hline
\end{tabular}

\subsection{Thermal properties}

Table 2 shows the changes in $T_{g}$ of the clay-reinforced E-P samples. Considering the reaction that occurs in the E-P system [26, 27], the addition of epoxy in the E-P formulations increased the glass transition temperature of the networks. The higher crosslinked material is expected to be formed when equimolar amounts of phenolic and epoxy are used (1:1 ratio, E-P(67/33)). However, in this system, the $T_{g}$ reaches a maximum value for the $50 / 50 \mathrm{E}-\mathrm{P}$ sample (phenol-epoxy ratio 2:1). To explain this maximum, note that for the system under study, the cross-linking density is not the only factor affecting the physical properties of the networks. As the compositions were varied to achieve phenol-epoxy equivalence ratios from $1: 1$ to $4: 1$, the epoxy concentration is not sufficient to connect the phenolic chains, leaving a large number of dangling chain ends that could act as plasticizer. Increasing the concentration of phenolic, there is a balance between the dangling chains that increase and the effect of glassy intermolecular forces that increase along this series, due to an increase in hydrogen bonding from the increased numbers of unreacted phenols.

Table 2 also shows the change in the $T_{g}$ for nanocomposites with various clay loadings. The thermal properties of nanocomposites containing 1:1 and 4:1 phenol-epoxy equivalent ratio exhibit a completely different behavior than the samples with $2: 1$ phenol-epoxy equivalent ratio. This observation is clear evidence of the effects of cross-linking density and the intermolecular forces due to the unre- acted phenol groups, as described previously. However, the general tendency of the $T_{g}$ is to decrease with increasing additions of nanoclay. Similar variations in $T_{g}$ have been reported for other nanocomposite systems [30, 31]. For example, Chen et al. [31] attributed such variation to the formation of an interphase between the silicate layers. An interphase is defined as the matrix material near the surface of the filler compound, where the matrix properties differ from the properties in the bulk matrix. In this case, the interphase between the nanoclay particles and the matrix may be affected by the cross-linking density, causing or contributing to the observed decrease in the glass transition temperature.

\subsection{Mechanical performance}

\subsubsection{Flexural and compressive properties}

Table 2 lists the measured flexural and compressive properties for the E-P/clay composites and unreinforced controls. For the pristine samples, the results show that the flexural modulus increases with decreasing ratio of epoxies to phenols. Tyberg et al. $[23,24]$ attributed this effect to a decrease in the network density, although there is no established relationship between modulus and network density. The addition of the nanoclays substantially increased the flexural modulus of the nanocomposites relative to the neat polymer. For example, $10 \mathrm{wt} \%$ of organoclay produced a $20 \%$ increase in flexural modulus. The mechanical properties of composites depend on multiple factors, including the aspect 
ratio of the filler, the degree of dispersion of the fillers in the matrix, and the adhesion at the fillermatrix interface $[32,33]$. In addition, the degree of exfoliation of the layered silicate in the polymer influences the modulus of nanocomposites [34, 35]. Several explanations have been proposed to explain the modulus enhancement observed in polymer layered silicate hybrids. Most explanations focus on the large surface area of the inorganic phase and the corresponding restricted mobility of the polymer chains [34, 36, 37]. In glassy-epoxy systems such as the present system, the stiffness improvement is generally attributed to an increase in the effective particle volume fraction in the nanocomposite [34]. In contrast, a surprising decrease in compressive and flexural strength is observed, despite the addition of a stiff reinforcement [35]. This decrease is attributed to clustering of nanoparticles, as noted from the TEM images (Figure 3a). In most cases, epoxy-based nanocomposites show no improvements in strength [35]. In fact, inhomogeneous microscale dispersions of the layered silicate dramatically lower the strength. This suggests that the strength of brittle matrix nanocomposites is primarily controlled by the dispersion of microscale silicate particles.

\subsubsection{Fracture properties}

All materials fractured in an unstable manner, however some differences in behaviour were observed among them. Samples with E-P(35/65) and E-P (50/50) exhibited complete brittle fracture as judged from the linearity of the load deflection records (Figure 4) and the features of the fracture

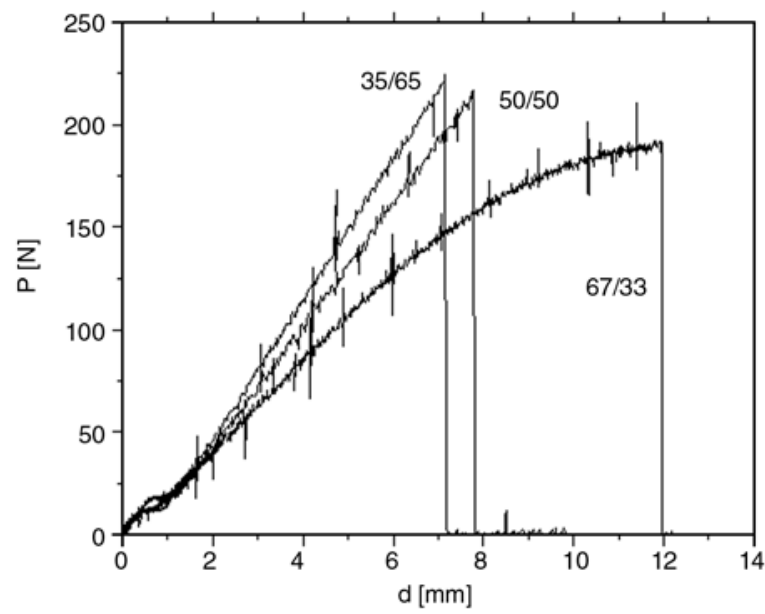

Figure 4. Load deflection curve of pristine samples $(P-$ load and $d$-deformation) surface. Load-time curves dropped to zero instantaneously upon reaching the maximum load. Samples with E-P(67/33) exhibited semi-brittle behaviour and developed limited plasticity ahead of the crack tip. The load increased first linearly and then non-linearly and displayed a drastic drop in coincidence with the sample failure. Features of load-displacement curves were not influenced by the addition of clay. All samples were within the Linear Elastic Fracture Mechanics condition, i. e., $P_{\max } /$ $P_{5 \%}<1.1$, and toughness obtained from them represent valid plane strain values satisfying size criteria (Equation (3)):

$B, a,(W-a)>2.5\left(\frac{K_{1 C}}{\sigma_{y}}\right)^{2}$

Figure 5 shows the dependence of fracture toughness, $\left(K_{1 C}\right)$ on clay content for the different E-P nanocomposites. The pure matrix toughness increases with increasing ratios of phenol to epoxy up to a threshold in E-P(50/50). This trend is consistent with expectations of increased toughness with the average molecular weight between crosslinks (increasing ratio of phenol-to-epoxy) up to a threshold, at which point the density of unconnected phenolic chains begins to dominate the properties [23-24]. Note that in the present system, an additional factor affected the physical properties of the networks. As the compositions were varied from epoxy-phenolic equivalent ratios of $1: 1$ to $1: 4$, the network densities decreased, but at the same time, the intermolecular forces increased as a result of increased hydrogen bonding from the large num-

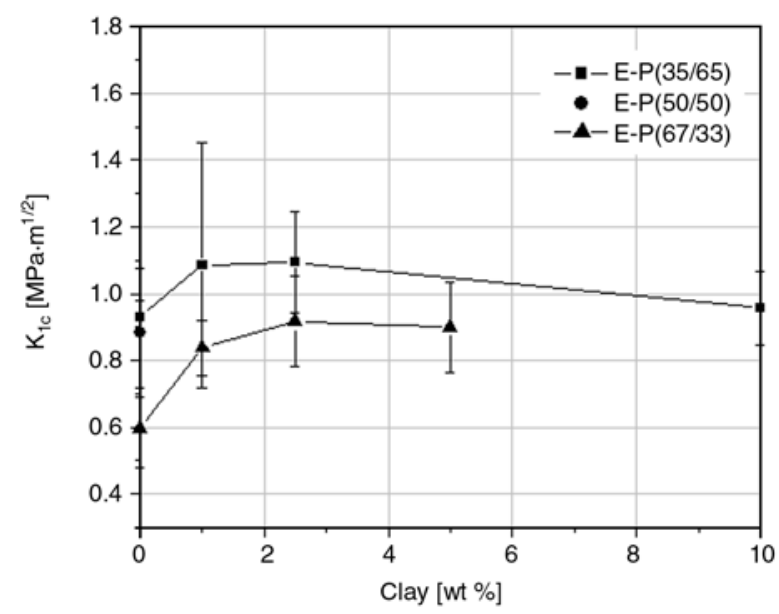

Figure 5. Fracture toughness the different E-P nanocomposites as a function of clay content 
ber of unreacted phenols. Both factors contributed to toughness in a complementary fashion.

The fracture toughness of some the E-P nanocomposites increased up to $70 \%$ over the unmodified resin. Microscale rigid particles generally tend to increase the toughness of brittle polymers but reduce toughness of ductile polymers [35]. The mechanisms governing fracture properties of thermoset layered silicate nanocomposites are likely to operate at the microscale. The increase in effective particle volume fraction is also likely to contribute to the fracture energy improvements.

SEM micrographs acquired from fracture surfaces of neat polymer samples and nanocomposites provide insight into the fracture mechanism. Typical findings are shown in Figure 6. The unreinforced matrix has a smooth crack surface, indicating that the resistance to crack propagation is low. In contrast, the nanocomposites exhibited a rougher fracture surface, filled with scale-like terraces and steps. The morphology derives from the presence of organoclay layers that force the crack to propagate along a stepped and tortuous path, thereby dissipating energy during fracture. Close observation revealed fine micro-cracks between the scale-like steps, indicating that the clay layers acted as stress concentrators and promoted the formation of the micro-cracks during loading.

Toughening effects of clay in epoxy/clay nanocomposites have been reported extensively [38-41]. Some investigators concluded that crack arrest and pinning [38], as well as massive shear deformation [41] were responsible for the observed toughening. Composites with a high E/P ratio matrix (Figure 6b) exhibited features described as massive shear yielding induced by the stress concentration of rigid nano particles [41]. As E/P ratio diminishes in matrixes (Figure 6c and d) fracture surfaces exhibited features consistent with crack pinning [42-43] as the dominant mechanism for toughening, and the rigid particles also enhance localized plastic deformation between particles. These results agree with the well known fact that plastic deformation of the matrix is limited in thermoset plastics with high crosslink density and microcrack is a main toughening mechanism [44, 45]. In these systems crosslink density increases and toughenability decreases with epoxy content.

The deformation zones generated ahead of the arrested crack-tip in 4 point bend tests are shown in

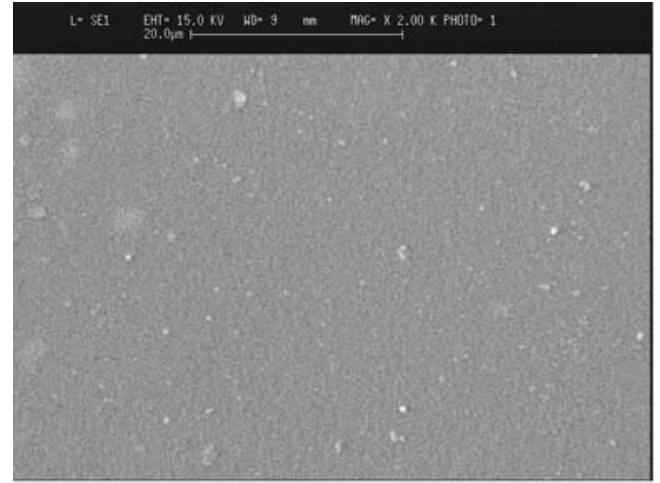

a)

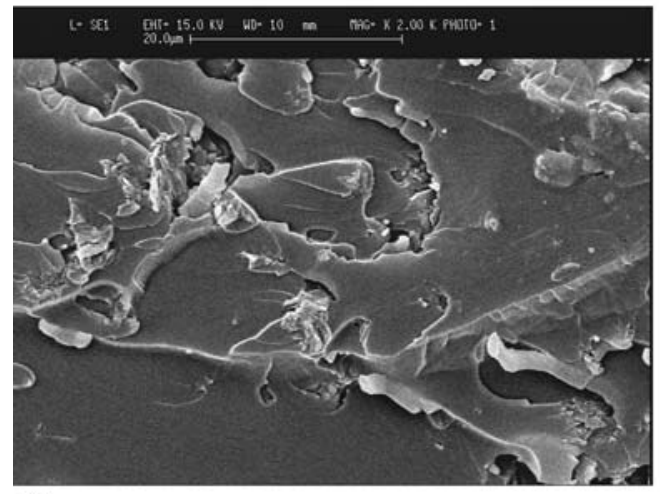

c)

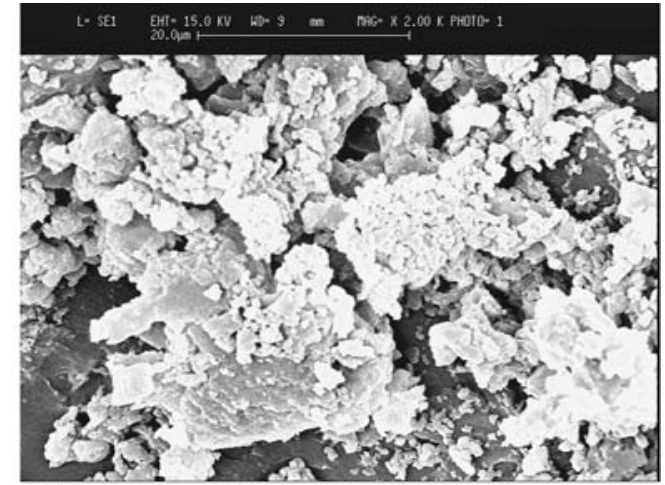

b)

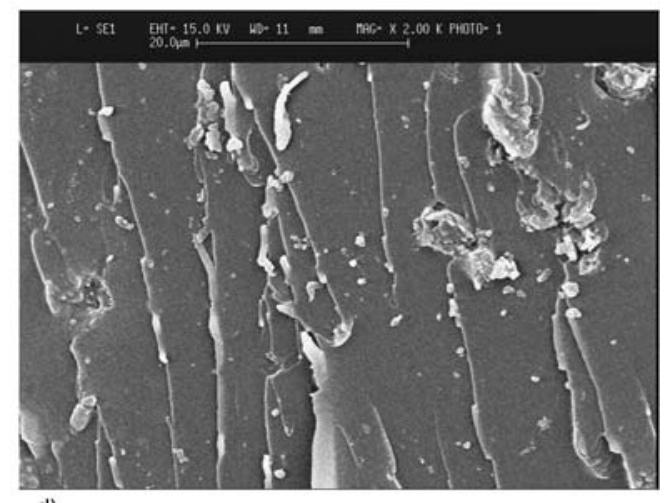

d)

Figure 6. SEM images of fracture surfaces a) E-P(35/65) matrix, b) E-P(35/65) with 2.5 wt\% clay, c) E-P(50/50) with 2.5 wt $\%$ clay, d) E-P(67/33) with 2.5 wt $\%$ clay 


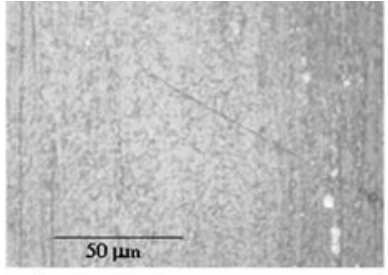

a)

Figure 7. Side views of crack-tip damage for a) E/P matrix and b) E/P with $10 \mathrm{wt} \%$ clay specimens under static loading conditions (SEDN-4PB experiments). (Matrix: E-P(35/65)

Figure 7. The bright field micrographs were obtained by transmission optical microscopy (TOM). The unreinforced sample exhibits a smooth crack surface, while the nanocomposites manifest crack trajectories that were tortuous and branched along the crack length.

The findings reported here indicate that multiple mechanisms are involved in the toughening of the current nanocomposites, including microcracking, crack deflection, crack pinning, and matrix shear in different ratios according to the crosslink density of the matrix. However, the toughness reached a maximum for nanocomposites with $2.5-5 \mathrm{wt} \%$ of clay content. This is a consequence of two competing processes associated with clay-induced microcracking. Both microcracking and microcrackenhanced crack deflection are important toughening mechanisms in these materials. Consequently, an increase in clay content will increase the extent of microcracking, and thus, the fracture toughness. On the other hand, as the inter-particle distance becomes smaller at increasing clay contents, the presence of weakly bonded particles resembles cavities ahead of a crack tip. This reduces the material resistance to fracture and forms an extension of the advancing crack. In light of this argument, the fracture toughness of the nanocomposite should decrease with clay content. The combination of the two competing effects gives rise to the maximum in toughness observed for nanocomposites with 2.5$5 \mathrm{wt} \%$ of clay content.

\section{Impact properties}

The dependence of material impact strength on clay content is shown in Figure 8. The error bars indicate the standard deviation.

Impact toughness increases with the change in E-P from 67/33 to 50/50, and a slight additional increase was observed with the change in E-P from

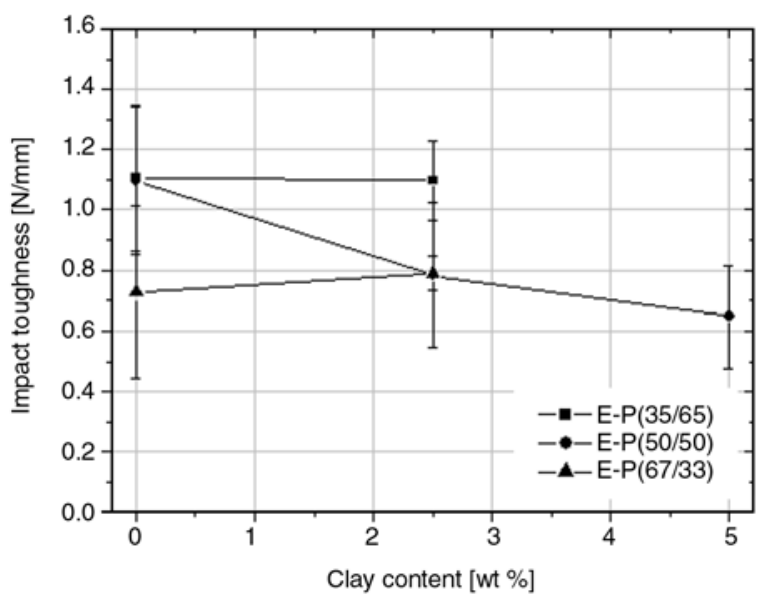

Figure 8. Impact toughness of evaluated nano-materials as a function of clay content

$50 / 50$ to $35 / 65$. This trend is similar to the case of fracture toughness measured at quasi-static loading rates. In nanocomposites, the impact strength decreased with increasing clay content, or no effect was found. This can be attributed to the presence of clay particle agglomerates, noted previously, that act as stress concentrators, diminishing impact strength, and the decreasing capability of matrixes to undergo viscoelastic and/or plastic deformation with increasing strain rate [46] SEM images of fracture surfaces from impact toughness tests are shown in Figure 9. The fracture surfaces of the nanocomposites showed irregular, micro-roughened topography consistent with fast crack growth [46-49].

Historically, thermosetting resins such as epoxies have key engineering limitations, including inherent brittleness and moisture uptake. The potential of nano-modifications to achieve an improved toughness-stiffness balance is the motivation for much research, yet general trends have not been conclusively demonstrated for the effects of nanomodifications on impact toughness [49]. However, it has been reported that in general, the impact strength decreases with increasing clay content, especially at high clay contents [49]. Our results suggest that while there was no significant effect of nanoclay additions on impact strength, energy dissipating mechanisms are rate-sensitive. This finding is in agreement with literature data in which the high strain rate attained under impact conditions limited the improvement in strength [43]. 


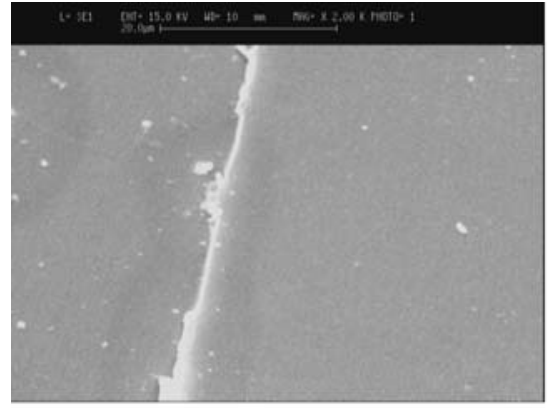

a)

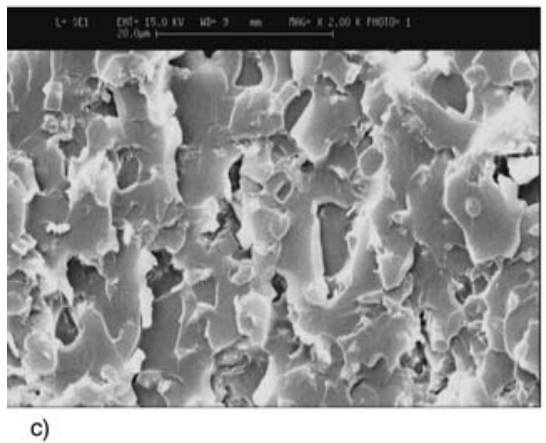

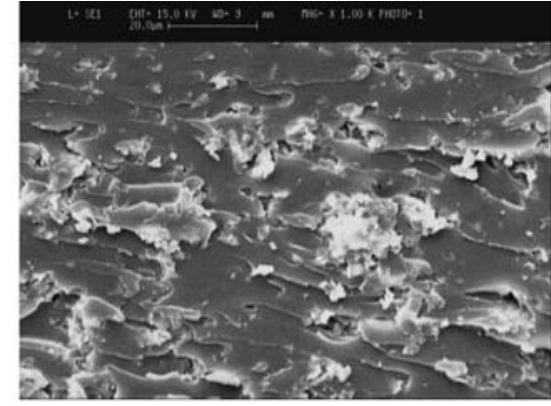

b)

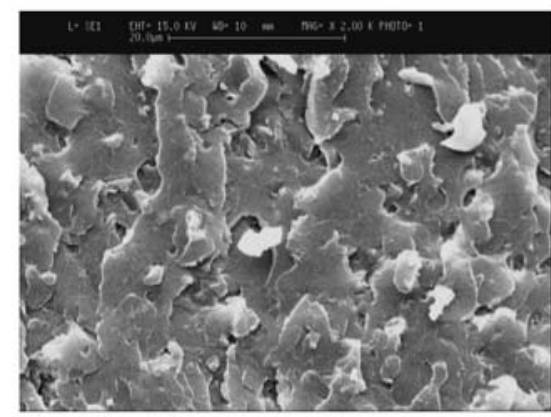

d)

Figure 9. SEM images of fracture surfaces from impact toughness tests a) E-P(35/65) matrix, b) E-P(35/65) with 2.5 wt $\%$ clay, c) E-P(50/50) with 2.5 wt\% clay, d) E-P(67/33) with 2.5 wt $\%$ clay

\section{Conclusions}

The relationship between the chemical network structures and the mechanical properties of epoxyphenolic nanocomposites has been elucidated. These nanocomposites show an increase in fracture toughness (70\% increase) and Young's modulus (20\% increase) compared to the matrix. These enhancements are achieved without a significant decrease in flexural strength. Fractography revealed several mechanisms that contribute to the increase in fracture toughness of the nanoreinforced samples, including micro-cracking, crack deflection, crack pinning, and matrix shear.

The results illustrate the potential to enhance the performance of polymers used for composite matrices through the addition of nanoclays, without diminishing the processing characteristics. Furthermore, the low loadings of organoclay silicates required to achieve these improvements offer promise for performance enhancements with only modest cost increments.

\section{Acknowledgments}

The authors are grateful to the Merwyn C. Gill Foundation for financial support.

\section{References}

[1] Okada A., Kawasumi M., Usuki A., Kojima Y., Kurauchi T., Kamigaito O.: Swelling behavior of montmorillonite cation exchanged for omega-amino acids by epsilon-caprolactam. Journal of Material Research, 8, 1174-1178 (1993).

[2] Kojima Y., Usuki A., Kawasumi M., Okada A., Kurauchi T., Kamigaito O.: Synthesis of nylon-6-clay hybrid by montmorillonite intercalated with epsiloncaprolactam. Journal of Polymer Science, Part A: Polymer Chemistry, 31, 983-986 (1993).

[3] Usuki A., Kojima Y., Kawasumi M., Okada A., Fukushima Y., Kurauchi T., Kamigaito O.: Mechanical-properties of nylon 6-clay hybrid. Journal of Material Research, 8, 1185-1189 (1993).

[4] Yano K., Usuki A., Okada A., Kuruauchi T., Kamigaito O.: Synthesis and properties of polyimide clay hybrid. Journal of Polymer Science: Part A: Polymer Chemistry, 31, 2493-2498 (1993).

[5] Okada A., Usuki A.: The chemistry of polymer-clay hybrids. Materials Science and Engineering, 3, 109115 (1995).

[6] Lan T., Pinnavaia T. J.: Clay-reinforced epoxy nanocomposites. Chemistry of Materials, 6, 22162219 (1994).

[7] Lan T., Kaviratna P. D., Pinnavaia T. J.: On the nature of polyimide clay hybrid composites. Chemistry of Materials, 6, 573-575 (1994). 
[8] Lan T., Kaviratna P. D., Pinnavaia T. J.: Mechanism of clay tactoid exfoliation in epoxy-clay nanocomposites. Chemistry of Material, 7, 2144-2150 (1995).

[9] Gilman J. W., Jackson C. L., Morgan A., Harris R.: Flammability properties of polymer-layered-silicate nanocomposites. Chemistry of Materials, 12, 18661872 (2000).

[10] Vaia R. A., Price G., Ruth P. N., Nguyen H. T.: Polymer/layered silicate nanocomposites as high performance ablative materials. Applied Clay Science, 15, 6792 (1990).

[11] Messersmith P. B., Giannelis E. P.: Synthesis and characterization of layered silicate-epoxy nanocomposites. Chemistry of Materials, 6, 1719-1723 (1994).

[12] Messersmith P. B., Giannelis E. P.: Synthesis and barrier properties of poly(epsilon-caprolactone)-layered silicate nanocomposite. Journal of Polymer Science Part A: Polymer Chemistry, 33, 1047-1052 (1995).

[13] Burnside S. D., Giannelis E. P.: Synthesis and properties of new poly(dimethylsiloxane) nanocomposites. Chemistry of Materials, 7, 1597-1600 (1995).

[14] Bharadwaj R. K., Mehrabi A. R., Hamilton C., Trujillo C., Murga M., Fan R., Chavira A., Thompson A. K.: Structure-property relationships in cross-linked polyester-clay nanocomposites. Polymer, 43, 36993705 (2002).

[15] Vaia R. A., Giannelis E. P.: Polymer nanocomposites: Status and opportunities. Material Research Society Bulletin, 26, 394-401 (2001).

[16] Park J. H., Jana S. C.: Mechanism of exfoliation of nanoclay particles in epoxy-clay nanocomposites. Macromolecules, 36, 2758-2768 (2003).

[17] Giannelis E. P.: Polymer layered silicate nanocomposites. Advanced Materials, 8, 29-35 (1996).

[18] LeBaron P. C., Wang Z., Pinnavaia T. J.: Polymer-layered silicate nanocomposites: an overview. Applied Clay Science, 15, 11-29 (1999).

[19] Yeh J. M., Liou S. J., Lai C. Y., Wu P. C., Tsai T. Y.: Enhancement of corrosion protection effect in polyaniline via the formation of polyaniline-clay nanocomposite materials. Chemistry of Materials, 13, 11311136 (2001).

[20] Fornes T. D., Yoon P. J., Hunter D. L., Keskkula H., Paul D. R.: Effect of organoclay structure on nylon 6 nanocomposite morphology and properties. Polymer, 43, 5915-5933 (2001).

[21] Manfredi L. B., Puglia D., Kenny J. M., Vasquez A.: Structure-properties relationship in resol/montmorillonite nanocomposite. Journal of Applied Polymer Science, 104, 3082-3089 (2007).

[22] Pappas J., Patel K., Nauman E. B.: Structure and properties of phenolic resin/nanoclay composites synthesized by in situ polymerization. Journal of Applied Polymer Science, 95, 1169-1174 (2005).

[23] Tyberg C. S., Bergeron K., Sankarapandian M., Shih P., Loos A. C., Dillard D. A., McGrath J. E., Riffle J. S., Sorathia U.: Structure-property relationships of void-free phenolic-epoxy matrix materials. Polymer, 41, 5053-5062 (2000).
[24] Tyberg C. S., Shih P., Verghese K. N. E., Loos A. C., Lesko J. J., Riffle J. S.: Latent nucleophilic initiators for melt processing phenolic-epoxy matrix composites. Polymer, 41, 9033-9048 (2000).

[25] Lin-Gibson S., Baranauskas V., Riffle J. S., Sorathia U.: Cresol novolac-epoxy networks: properties and processability. Polymer, 43, 7389-7398 (2000).

[26] Auad M. L., Zhao L., Nutt S. N., Sorathia U.: Fireresistant high-performance epoxy-phenolic foam. in '49th International SAMPE Symposium and Exhibition, Long Beach, USA', 305-315 (2004).

[27] Auad M. L., Zhao L., Shen H., Nutt S. R., Sorathia U.: Flammability properties and mechanical performance of epoxy modified phenolic foams. Journal of Applied Polymer Science, 104, 1399-1407 (2007).

[28] Sue H-J., Yee A. F.: Study of fracture mechanisms of multiphase polymers using the double-notch 4-pointbending method. Journal of Materials Science, 28, 2975-2980 (1993).

[29] Arias M. L., Frontini P. M., Williams R. J. J.: Analysis of the damage zone around the crack tip for two rubber-modified epoxy matrices exhibiting different toughenability. Polymer, 44, 1537-1546 (2003).

[30] Kornmann X., Thomann R., Mulhaupt R., Finter J., Berglund L. A.: High performance epoxy-layered silicate nanocomposites. Polymer Engineering and Science, 42, 1815-1826 (2002).

[31] Chen J-S., Poliks M. D., Ober C. K., Zhang Y., Wiesner U., Giannelis E.: Study of the interlayer expansion mechanism and thermal-mechanical properties of surface-initiated epoxy nanocomposites. Polymer, 43, 4895-4904 (2002).

[32] Wang K., Wu J., Chen L., He C., Toh M.: Mechanical properties and fracture behavior of epoxy nanocomposites with highly exfoliated pristine clay. in 'ANTEC conference proceedings Chicago, USA', Vol 2, 1820-1824 (2004).

[33] Isik I., Yilmazer U., Bayram G.: Flexural properties and morphology of impact modified epoxy-organoclay nanocomposites. in 'ANTEC conference proceedings Chicago, USA', Vol 3, 2961-2965 (2004).

[34] Kornmann X., Lindberg H., Berglund L. A.: Synthesis of epoxy-clay nanocomposites. Influence of the nature of the curing agent on structure. Polymer, 42, 4493 4499 (2001).

[35] Zerda A. S., Lesser A. J.: Intercalated clay nanocomposites: Morphology, mechanics, and fracture behavior. Journal of Polymer Science, Part B: Polymer Physics, 39, 1137-1146 (2001).

[36] Choi M. H., Chung I. J.: Mechanical and thermal properties of phenolic resin-layered silicate nanocomposites synthesized by melt intercalation. Journal of Applied Polymer Science, 90, 2316-2321 (2003).

[37] Lan T., Kaviratna D., Pinnavaia T. J.: Epoxy selfpolymerization in smectite clays. Journal of Physics and Chemistry of Solids, 57, 1005-1010 (1996). 
[38] Becker O., Varley R., Simon G.: Morphology, thermal relaxation and mechanical properties of layered silicate nanocomposites based upon high-functionality epoxy resins. Polymer, 43, 4365-4373 (2002).

[39] Kornmann X., Thomann R., Mulhaupt R., Finter J., Berglund L. A.: Synthesis of aminecured, epoxy-layered silicate nanocomposites: The influence of the silicate surface modification on the properties. Journal of Applied Polymer Science, 86, 2643-2652 (2002).

[40] Zilg C., Mülhaupt R., Finter J.: Morphology and toughness/stiffness balance of nanocomposites based upon anhydride-cured epoxy resins and layered silicates. Macromolecular Chemistry and Physics, 200, 661-667 (1999).

[41] Ratna D., Manoj N. R., Varley R., Singh Raman R. K., Simon G. P.: Clay-reinforced epoxy nanocomposites. Polymer International, 52, 1403-1407 (2003).

[42] Maazouz A., Sautereau H., Gerard J. F.: Hybrid-particulate composites based on an epoxy matriz, a reactive rubber, and glass beads: morphology, viscoelastic, and mechanical properties. Journal of Applied Polymer Science, 50, 615-626 (1993).

[43] Bandyopadhyay S.: Macroscopic fracture behavior: Correlation with microscopic aspects of deformation. in 'Toughened plastics I. Science and engineering' (eds.: Riew C. K., Kinloch A. J.). American Chemical Society, Washington D.C., 211-258 (1993).
[44] Lu F., Plummer C. J. G., Cantwell W. J., Kausch HH.: Toughening mechanisms in modified epoxy resins with different crosslink densities. Polymer Bulletin, 37, 399-406 (1996).

[45] Shiann H. L., Nauman E. B.: Effect of cross-linking density on the toughening mechanisms of rubbermodified thermosets. Journal of Materials Science, 26, 81-90 (1991).

[46] Yee A. F., Du J., Thouless M. D.: Toughening of epoxies. In 'Polymer Blends' (Eds.: Paul D. R, Bucknall C. B.), John Wiley and Sons, New York, 225-267 (2000).

[47] Chan J., Gillham J. K., Kinloch A. J., Shaw S. J.: Rubber-modified epoxies: morphology, transitions, and mechanical properties. in 'Rubber-modified thermoset resins' (eds.: Riew C. K., Gillham J. K.), American Chemical Society, Washington D.C., 261-279 (1984).

[48] Bascom W. D., Hunston D. L.: Fracture of elastomermodified epoxy polymers. in 'Rubber-toughened plastics' (ed.: Riew K.), American Chemical Society, Washington D.C., 135-172 (1989).

[49] Isik I., Yilmazer U., Bayram G.: Impact modified epoxy/montmorillonite nanocomposites: synthesis and characterization. Polymer, 44, 6371-6377 (2003). 